\title{
ИННОВАЦИОННЫЙ ПОТЕНЦИАЛ СОЦИАЛЬНО-ЭКОНОМИЧЕСКОЙ СИСТЕМЫ: КАТЕГОРИАЛЬНЫЙ АППАРАТ
}

\author{
(c) 2019 Безденежных Т.И. \\ доктор экономических наук, профессор \\ Санкт-Петербургский государственный экономический университет, Россия, Санкт-Петербург \\ E-mail: girii@mail.ru \\ (C) 2019 Хейфиц Б.И. \\ кандидат экономических наук, доцент ЛКИТиУ \\ МГУТУ им. К.Г. Разумовского (ПКУ), Россия, Москва \\ E-mail: b.heifits@yandex.ru
}

В статье рассмотрен категориальный аппарат инноватики, в частности, инновационный потенциал социально-экономической системы. Исследованы подходы к следующим понятиям: инноватика, практическое применение инноватики, инновационное развитие, инновационная деятельность, инновация, инновационный потенциал. Проведен анализ сущностно-содержательной характеристики инновационного потенциала. Исследован процесс разработки и внедрения инноваций в управленческую практику должен с использованием модели ADKAR.

Ключевые слова: инновационное-развитие, инноватика, инновация, инновационный потенциал, системный подход

Условия функционирования постиндустриальной модели общества характеризуются использованием новых инструментов, направленных на развитие научно-технического прогресса.

Методология использования инновационных подходов к развитию общества отражена в теоретических положениях относительно новой науки - инноватики. Наиболее общее определение инноватики представлено в журнале «Business Times»: «...Инноватика - это область знаний, охватывающая методы и способы организации инновационной деятельности» [7]. Более расширенное толкование данного понятия делает акцент на управленческом аспекте: «..инноватика - это область знаний о сущности инновационной деятельности, а также её организации и управлении инновационными процессами, которые обеспечивают трансформацию новых знаний в востребованные обществом новшества как на коммерческой основе (коммерциализация результатов научнотехнической и творческой деятельности), так и некоммерческой базе (например, инновации в социальной сфере)» [1]. Таким образом, инноватика направлена на выработку, распространение и внедрение инноваций в практическую деятельность, то есть на реализацию инновационной активности отдельных объектов управления. Основной целью инноватики является

выработка решений, направленных на внедрение новшеств в различных сферах социальноэкономической деятельности.

Инноватика является механизмом стратегического развития, так как предполагает организацию процесса перевода объекта в новое состояние в течение определенного периода времени. Основным инструментом инноватики является инновационная активность, реализуемая посредством трансформации внешних и внутренних мотиваторов системы в конкретизацию целеполагания и разработку стратегии опережающего развития. При этом в качестве индикаторов эффективности реализуемых стратегических задач выступают количественные и качественные характеристики системы.

Инноватика является междисциплинарной категорией, включающей в себя методологические разработки из психологии, социологии, кибернетики, экономики, теории управления. Междисциплинарность понятия «инноватика» выражается в использовании различных методологических инструментов, позволяющих всесторонне развивать теоретическую и практическую базу для формирования концепции успешного инновационного развития [14].

Наиболее значимую роль в формировании методологического аппарата инноватики играет теория систем. Инноватика имеет два маги- 
стральных направления исследования: методологическое и практическое. Первое основано на выявлении и формулировании устойчивых связей, зависимостей и структурной соподчиненности между характеристиками объекта, имеющими различную природу формирования. Практическая реализация принципов инноватики нацелена на повышение эффективности отдельных субъектов общественноэкономической системы. Привлечение методологического инструментария инноватики, разработанного на основе теоретических разработок экономических и управленческих дисциплин, имеет основной целью формирование принципов эффективного управления, то есть выработку механизмов «практики инноватики».

Формирование концепции инновационного опережающего развития для всех компонентов общественно-экономической системы затрагивает управленческие аспекты и реализуется через такие понятия как «управление инновациями», «управление изменениями», «управление инновационными процессами» и т.п. Использование «управленческой надстройки» необходимо для разработки новых принципов, способов и форм организации различных процессов, происходящих как в экономической, так и социальной сферах системы.

Дальнейшее исследование категорийного аппарата необходимо проводить после определения объекта практического применения инноватики. В целях решения государственных стратегических задач таким объектом выступает социально-экономическая система. Наиболее полным представляется определение, сформулированное И.Б. Береговой: «Социальноэкономическая система - это целостная совокупность взаимосвязанных и взаимодействующих социальных и экономических институтов (субъектов) и отношений по поводу распределения и потребления материальных и нематериальных ресурсов, производства, распределения, обмена и потребления товаров и услуг [3]. В рамках междисциплинарного подхода к инноватике основополагающую роль играет методология теории систем. Любая социально-экономическая система имеет выраженные системные свойства, основными из которых являются эмерджентность (интегративность), иерархичность, целостность. В процессе управления инновациями процесс их внедрения должен не только читывать интегративный характер изменений, но и способствовать получению положительного синергетического эффекта, оценка которого достигается с помощью разработки критериев для каждого элемента внедряемой системы (подсистемы).

Любая социально-экономическая система может быть конкретизирована с позиции временного и пространственного аспектов, способов и методов развития, а также привлекаемого для этого инструментария. Соответственно, социально-экономическая система имеет конкретное воплощение в форме различных государственных, политических, частно-предпринимательских и иных образований.

Механизм функционирования каждого типа социально-экономической системы обуславливается историческими закономерностями, условиями внешней среды, внутренними законами развития системы. Логика создания и развития социально-экономической системы всегда строится на принципе «от простого к сложному».

Социально-экономическая система может быть охарактеризована также в категориях «открытая-закрытая». Естественно, любая социально-экономическая система представляется открытой, так как ее функционирование определяется, в первую очередь, совокупностью взаимосвязей с внешней средой. В тоже время социально-экономическая система является и закрытой (замкнутой), так как одной из задач ее функционирования выступает сохранение и воспроизводство выработанных механизмов существования. Успешность в достижении целей и задач социально-экономической системы осуществляется через инновационное развитие, под которым подразумевается «..... целенаправленная деятельность, направленная на обеспечение долгосрочной экономической устойчивости социально-экономических систем посредством эффективного использования их потенциала к преобразованию условий хозяйствования в соответствии с тенденциями развития общественных потребностей и производства» [15]. Инновационное развитие реализуется только при условии достижения обществом определенного уровня научно-технического прогресса, сформированности его запросов на опережающее развитие, наличия «критического» объема компетенций элементов системы и понимания руководством необходимости внедрения инноваций.

Центральным понятием инноватики явля- 
ется «инновация». В научной литературе выделяют пять подходов, определяющих инновации как систему, процесс, изменение, средство, результат [10].

Изучение инновации как системы и процесса основано на методологии теории систем и проявляется в исследовании механизмов перехода инновации по различным этапам жизненного цикла. Процесс разработки и внедрения инноваций в управленческую практику должен реализовываться с использованием модели ADKAR (awareness - осознание необходимости изменений, desire - желание, knowledge - понимание, как это сделать, ability способности и практическая реализация навыков, reinforcement - обеспечение устойчивости изменений). Ее реализация невозможна без понимания системно-структурных взаимосвязей, формируемых методологическим аппаратом инноватики. Структурный элемент модели «ability» - наиболее важный в процессе управления инновациями, таккак только наличие необходимого уровня компетенций и способностей к переходу на новые методы и способы работы позволят реализовать весь инновационный процесс.

Результат инноваций можно рассматривать с двух позиций: как внедренные в практику новые технологии, продукты, процессы и т.п., и как новую идею, не имеющую материального воплощения. Рассмотрение инновации как новой идеи подразумевает в качестве результата выработку «дорожной карты» реализации идеи, включающей в том числе и определение источников финансирования.

Разработка программы внедрения каждого типа инноваций должна проводиться с помощью различной методологической базы, которую предоставляет инноватика. Противоречия между мышлением и практической деятельностью, целью и результатом возникают постоянно и требуют разрешения [8].

Понятие «инновационная деятельность» наряду с понятиями «инновация» и «инновационный потенциал» являются основополагающими в категориальном аппарате инноватики. В общем смысле, инновационная деятельность может рассматриваться как способ преобразования существующих элементов системы в более оптимальное состояние с помощью достижений научно-технического прогресса. Понятие «оптимальности» при этом формулируется на стадии выработки целевых показателей и определяет уровень превышения количественных и качественных характеристик системы над отчетными (существующими). По своей сущности инновационная деятельность является стратегической, так как направлена на получение новых характеристик объекта в будущем. Кроме того, инновационная деятельность проводитсяс использованием механизмов проектного управления, так как ее планирование и реализация основываются на учете таких параметров как последовательность, динамичность, определенность сроков достижения, конкретизация ресурсной базы и т.п.

Понятие «инновационный потенциал» основывается на характеристиках внутренней среды системы, основополагающими из которых являются научно-техническая база предприятия, уровень восприимчивости инноваций персоналом, его образовательный и профессиональный уровень, внутрисистемная инновационная инфраструктура, возможности взаимодействия с другими предприятиями, непосредственно или косвенно заинтересованных в реализации инноваций [12]. Инновационный потенциал следует рассматривать с позиции системного подхода, так как он является совокупностью тех или иных инноваций, формируемых как внутренними ресурсами системы, так и приобретаемыми из внешней среды. В результате формируется определенная структура инноваций, направленных на повышение эффективности функционирования системы. Наличие инновационного потенциала системы определяется на основе оценки уровня научно-технической составляющей системы, доли внедрения результатов научных исследований в практическую деятельность, состояния организационного и институционального аппарата, подразумевающего создание оптимального механизма процесса выработки и реализации управленческих решений, степени компетентности различных типов трудовых ресурсов.

В настоящее время понятие «инновационный потенциал» имеет достаточно широкую степень методологической разработанности. Согласно [5], «инновационный потенциал - «способность системы к трансформации фактического порядка вещей в новое состояние с целью удовлетворения существующих или вновь возникающих потребностей». Краюхин Г.А. определяет инновационный потенциал как сово- 
купность кадровых, материально-технических, информационных и финансовых ресурсов, обслуживаемых соответствующей инфраструктурой, предназначенной для реализации нововведений [9]. Инновационный потенциал может быть представлен как «...совокупность научно-технических, производственных, технологических, кадровых, инфраструктурных, финансовых, правовых и иных возможностей хозяйствующих субъектов региона обеспечить восприятие и диффузию инноваций» [13]. Более общее определение, характеризующее потенциал общественной системы, дает Жиц Г.И.: «Инновационный потенциал - это количество экономических ресурсов, которые в каждый конкретный момент общество может использовать для своего развития» [6]. Таким образом, инновационный потенциал подразумевает под собой не конкретную реализацию инноваций (внедрение их в практическую плоскость), а наличие у социально-экономической системы возможности, способности и готовности разрабатывать и внедрять инновации различных видов и типов. Субъектами инновационного потенциала выступают ресурсы социально-экономической системы: финансовые, трудовые, информационные, материальные и др.), представляющие собой характеристику каждого элемента (подсистемы) в конкретный период времени.
По своей сущности инновационный потенциал выступает инструментом инноватики в различных видах и типах систем. Системно-структурный подход к организации социально-экономической системы подразумевает построение программы разработки и внедрения инноваций во все ее элементы (подсистемы). Эффективность практической реализации инноваций возможна только при полном понимании управленческой надстройкой необходимости детальной и перманентной процедуры формирования, внедрения и закрепления инноваций во всех организационных сферах.

Совокупность теоретических подходов к определению инновационного потенциала социально-экономической системы может быть представлена в виде схемы (рисунок 1) [4].

Предложенные аспекты исследования понятия инновационный потенциал отражают основные направления инновационной активности системы, направленной на формирование способности и готовности элементов системы к развитию инновационной составляющей. Основополагающим компонентом инновационного потенциала выступает кадровая составляющая, определяемая как совокупность трудовых ресурсов, обладающих объемом знаний, навыков и умений, необходимых для эффективного функционирования в условиях постиндустриального

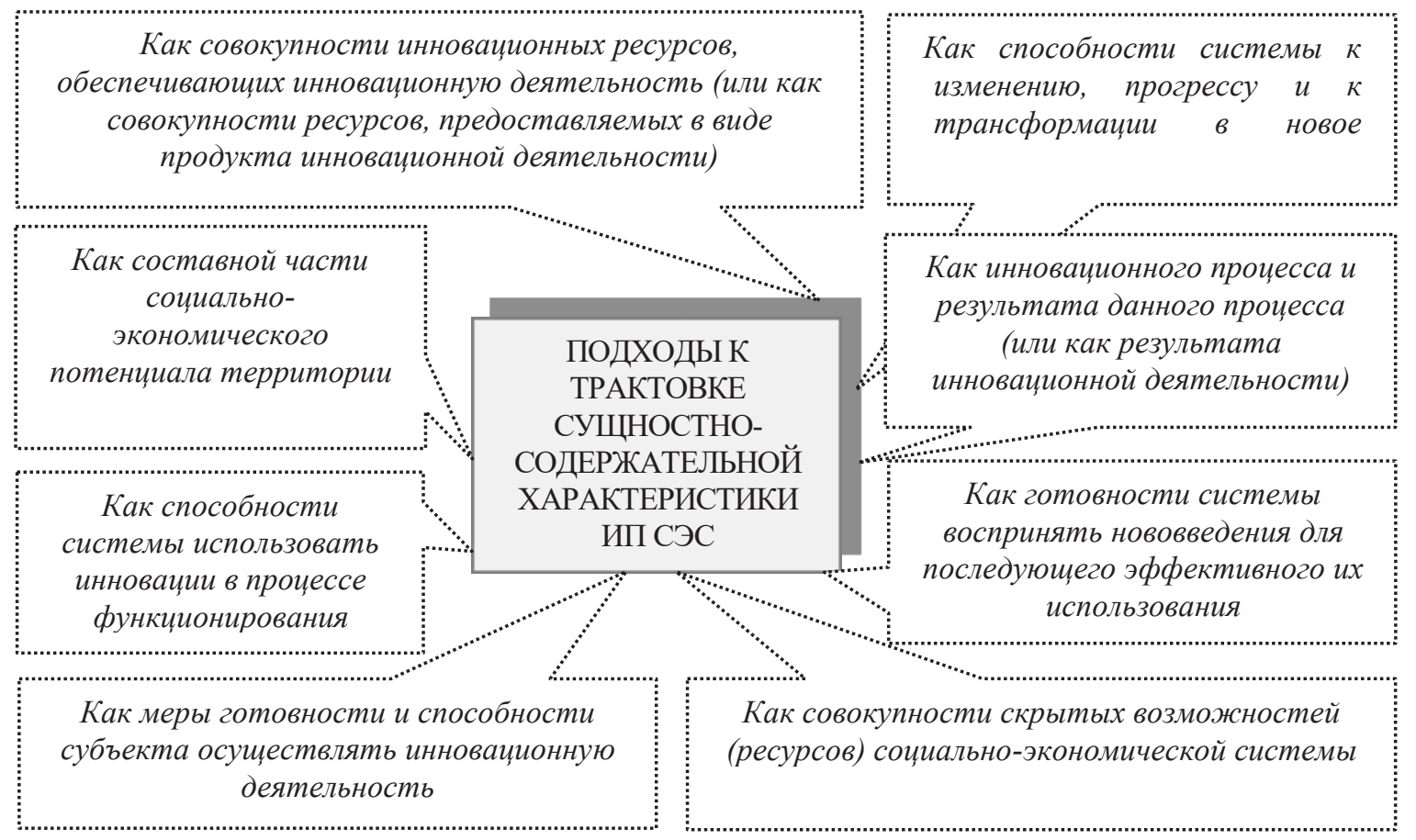

Puc. 1. Анализ сущностно-содержательной характеристики инновационного потенциала [4] 
информационного общества.

Понятие «инновационный потенциал» имеет свои особенности для каждого объекта управления.

Инновационный потенциал региона можно определить, как комплекс «организационно- экономических и правовых условий создания, освоения и распространения инноваций» [11], или как «часть экономического потенциала, выраженная в виде научно-исследовательских, проектноконструкторских, технологических организаций, экспериментальных производств, опытных разработок, персонала научно-исследовательских организаций, их квалификациии способности к нестандартным новаторским идеям» [2]. В целом, инновационный потенциал региона представляет собой совокупность интеллектуальных, материально-технических ресурсов и потенциальных возможностей отдельных субъектов региона, направленных на осуществление стратегии опережающего развития.Инновационный потенциал региона является составной частью социально-экономического потенциала территории и выступает компонентом пространственной инновационной сети, объединяющей различные отрасли народного хозяйства, представленные в конкретном регионе.

Инновационный потенциал отрасли народного хозяйства определяется наличием синергетического эффекта при осуществлении инновационной активности субъектов отрасли.

Оценка инновационного потенциала должна проводиться на первоначальном этапе управления инновациями в каждом конкретном случае при внедрении отдельной инновации. Кроме того, необходимо проводить оценку основных параметров системы после завершения процесса внедрения инноваций. Для этого применяются такие научные методы инноватики, как «синтез-анализ», «восхождение от простого к сложному», «моделирование». Для проведения качественной и количественной оценки результативности каждого этапа внедрения инноваций необходимо проведения ранжирования оцениваемых факторов и выработки критериального результирующего показателя.

Разработка программы инновационной деятельности системы основывается на сопоставлении результатов различных способов организации производственного процесса и определении наиболее оптимального по выбранному критерию. В рамках выработки имитационных моделей разрабатываются научные гипотезы о предполагаемом поведении субъектов социальной системы при различных сочетаниях производственных ресурсов. При этом оцениваются не только существующие возможности различных элементов организационного процесса, но и потенциально вероятные стратегии поведения. Далее проводятся экспериментальные исследования разработанных моделей организационных систем, и формируется перечень наиболее достоверных вариантов развития системы. Полученные в результате моделирования альтернативные прогнозы развития системы выступают в качестве базы при разработке стратегии инновационной деятельности.

\section{Библиографический список}

1. Академик. Словари и энциклопедии [Электронный ресурс]. https://dic.academic.ru/dic.nsf/ruwiki/1506378 Дата обращения: 28.11 .2018).

2. Аюшеева Л.А. Совершенствование управления развитием ресурсно-инновационного потенциала региона. // Автореферат диссертации на соискание ученой степени кандидата экономических наук. - Красноярск,2007.- 22 c.

3. Береговая И.Б. Управление качеством и конкурентоспособностью социально-экономических систем. Учебное пособие.- Челябинск: Изд. Центр ЮУрГУ, 2015. - 227 с.

4. Волчкова И.В., Вотякова И. В., Воробвева Е.С., Недоспасов А. А., Недоспасова О.П. Инновационный потенциал территориальных социально-экономических систем: сущностно-содержательный аспект // Сборник статей V Международной научно-практической конференции: в 3 ч. 2017. - Пенза, Издательство: Наука и просвещение, 2017.- С. 114-117.

5. Добров Г.М., Тонкаль В.Е., Савельев А.А. и др. Научно-технический потенциал: Структура, динамика, эффективность.- Киев: Наукова думка, - 1987.- 347 с.

6. Жиц Г.И. Способности и возможности: рассуждения о некоторых аспектах методологии оценки влияния инновационного потенциала на развитие социально-экономических систем различного уровня сложности // Инновации. - 2008. - № 11.- С. 102-107. 
7. Журнал о бизнесе в России и за рубежом «Businesstimes» [Электронный pecypc]http://btimes.ru/dictionary/ innovatika Дата обращения: 29.11.2018).

8. Капустина, Н.В. Методология управления развитием организации на основе риск-менеджмента: автореферат дис. ... доктора экономических наук / Рос. акад. нар. хоз-ва и гос. службы при Президенте РФ. Ростовна-Дону, 2015

9. Краюхин Г.А., Шабайкова Л. Ф. Закономерности и тенденции инновационных процессов.- СПб.: СПбГИЭА,1995.- 250 c.

10. Марабаева Л.В. Основы инновационного менеджмента: учеб. пособие / Л.В. Марабаева, В.Н. Кечемайкин, О.А. Соколов.-Саранск: Тип. «Крас. Окт.», 2004. - 322 с.

11. Матвиенко С.В. Формирование региональных и макрорегиональных инновационных систем при переходе к постиндустриальной экономике.-СПб.: СПбГИЭУ,-2005.- 98 с.

12. Матузов Ю.И. Теоретические и методические подходы к формированию стратегии инновационного развития предприятий // Автореферат диссертации на соискание ученой степени кандидата экономических наук, Воронеж, 2012-24 с.

13. Монастырный Е.А. Термины и определения в инновационной сфере // Инновации- 2008.- № 2.- С. $28-31$.

14. Тульчинский Г.Л. Междисциплинарность. Проективный философский словарь [Электронный ресурс]- СПб.: Алетейя, 2003. 512 c. http://hpsy.ru/public/x3025.htm Дата обращения 30.11.2018

15. Филибокова Л. Ю. Инновации и интеллектуальный потенциал в малом предпринимательстве: сущность, методические подходы к оценке. // Управление экономическими системами. Электронный научный журнал. № 2, 218, С. 84. [Электронный ресурс] https://cyberleninka.ru/article/v/innovatsii-i-intellektualnyy-potentsialv-malom-predprinimatelstve-suschnost-metodicheskie-podhody-k-otsenke - Дата обращения 01.12.2018 